\title{
COMPUTER COMPATIBLE REGISTERS FOR GENERAL PRACTICE AND RESEARCH
}

\author{
M. BERKELEY, N. C. H. STOTT, R. C. MACNAIR, AND W. H. PRICE \\ MRC Clinical and Population Cytogenetics Unit, University Department of Medicine, \\ Western General Hospital, Edinburgh, and General Practice
}

The trend for general practitioners to work together in group practices and health centres, the emergence of the health team in general practice, the mobility of the population, the complexity of medical care, and the increase in chronic disease make it desirable to develop a system to identify and locate patients quickly and accurately. Furthermore, the general practitioner, as the clinician responsible for the continuing care of a registered list of patients many of whom are first-degree relatives, is ideally placed to undertake further research into genetic, epidemiological, and clinical problems. However, the existing records and registers are not sufficiently accurate, accessible or convenient. The inflation of the registered population over the actual population varies with time and place. It has been reported as $20 \%$ by Morrell, Gage, and Robinson (1970) and as 5 to $10 \%$ by Ockenden and Bodenham (1970), while the increase of the registered population, compared with the actual increase in England and Wales from 1963 to 1968, was reported by Clarke (1971) as being inflated by one-third.

This paper describes the experience gained in establishing and manually maintaining an accurate register of a group practice population as a preliminary exercise to population registration on a larger scale, and as a basis of a sampling frame for population cytogenetic research.

\section{MeTHODS}

Initial listing is made from the personal clinical records held at the practice premises. The identification data, including an allocated serial number, are punched directly on 80-column Hollerith cards (Figure 1), all records being committed to punched cards, however incomplete their data. All punched data are verified from the source documents. As the records are already in approximate alphabetical order, a listing of the cards on a line printer after only minimal order correction immediately gives a crude practice register.

\section{VALIDATION}

To identify and correct the several possible types of error in the crude listing, advantage is taken of the estimated $67 \%$ of individuals who present annually at the doctor's premises (Logan and Cushion, 1958). Approximately 60 to $65 \%$ of these patients are also able to provide information about other household members in the same practice. To assist the receptionist in checking these other patients, a set of cards is duplicated by machine and manually sorted by surname and address to provide a direct printout of household groupings with intra-group ordering by Christian names and initials. It is this ledger which is used for checking and correcting the initial register (Figure 2).

(a)

(b)

\begin{tabular}{|c|c|c|c|}
\hline 01234 & SMITH.MARY* 19. HICH ST, SE & O OIMFO7IC & 045 \\
\hline 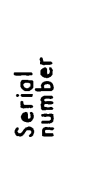 & Surname, First name, Initials * Address $£$ & 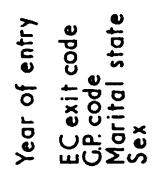 & $\begin{array}{l}\text { Date } \\
\text { of } \\
\text { birth }\end{array}$ \\
\hline
\end{tabular}

Fig. 1-The layout of the 80-column Hollerith card: (a) a sample of interpreted punched card; (b) description of data content (* indicates end of name; $£$ indicates end of address). 
- HOUSEHOLO

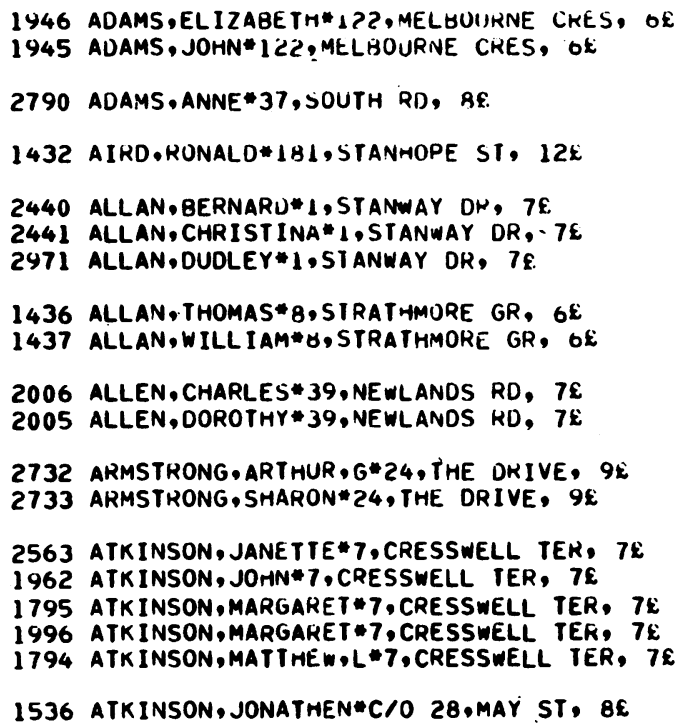

OUMF 290722 $08 M M 170420$

$08 S F 121245$

$08 \mathrm{MZ20904}^{2}$

$08 M M 041042$ 0 OMF 150245 O8SM220366

$08 M M 151140$ $08 S M \angle 50469$

O8MMO10199 $08 M F 191100$

$08 M M 170235$ 08SF 270565

08SF 091165 O8SM190361 $08 M F 240134$ O8SF 121264 O४MM070930

$08 S M 170436$

FIG. 2-Register of 'household' groups (fictitious data).

At the end of the first year all unchecked patients were circularized with a questionnaire asking them to confirm the identification data on their medical record and to amend them if necessary.

Information on the completeness of family registration with an individual group practice and the adequacy of the surname/address groups has been estimated by an examination of the households of 270 patients who were the consecutive referrals from the practice to a general medical out-patient department. The following details were obtained during home interviews:

(a) number of persons with same surname in the household;

(b) number of persons with different surnames in the household;

(c) household members registered in the study practice.

\section{Updating Procedure}

The register is kept up to date from an 'IN' book, an 'OUT' book, and notifications to the Executive Council of changes of circumstances.

Identification data for each new patient are recorded in the 'IN' book in such a sequence that the information can be directly recorded on 80 column punched cards.

The details of patients who leave the practice are recorded in the 'OUT' book when the medical record envelopes are recalled by the Executive
Council. The punched cards for these patients are marked with an exit code indicating the reason for leaving the practice.

The changes of name and address which are routinely notified to the Executive Council (on form E.C.1.C.) are recorded on carbon duplicates of these forms and are kept for periodic updating of the practice registers.

\section{Card Files}

For manual operation of the registers, separate alphabetical and surname/address card files are maintained and regularly updated. In this way repeated manual or mechanical re-sorting of a single file is avoided.

ResUlts
INITIAL REGISTRATION
The initially listed population amounted to 6,074 patients. The National Health Service (N.H.S.) number was missing in $16 \%$ of records, and there was no date of birth in $7.8 \%$ of female records or in $8.4 \%$ of male records.

\section{VALIDATION}

During the year, the entries for 4,431 patients, i.e., $73 \%$ of the population initially listed, were confirmed or corrected. Validation of the surname/ address groupings was achieved for $61 \%$ of the groups, the other $39 \%$ comprising $83.4 \%$ single person groups and $16.6 \%$ groups of two persons or more. 
TABLE I

REMOVALS FROM PRACTICE LIST BY AGE, SEX, AND EXIT CODE DURING 1970 (list size 1 January 1970 was 6,074)

\begin{tabular}{|c|c|c|c|c|c|c|c|}
\hline Age (yr) & $\begin{array}{c}\text { Died } \\
\text { (D) }\end{array}$ & $\begin{array}{c}\text { Emigrated } \\
\text { (E) }\end{array}$ & $\begin{array}{l}\text { Removal after } \\
\text { notifying } \\
\text { Doctor } \\
\text { (N) }\end{array}$ & $\begin{array}{l}\begin{array}{c}\text { Removal } \\
\text { from } \\
\text { E.C. Area } \\
\text { (R) }\end{array} \\
\text { (R) }\end{array}$ & $\begin{array}{l}\text { National } \\
\text { Service } \\
\text { (S) }\end{array}$ & $\begin{array}{l}\text { Removal } \\
\text { within } \\
\text { E.C. Area } \\
\text { (X) }\end{array}$ & Total \\
\hline $\begin{array}{l}\text { Male } \\
0-14 \\
15-44 \\
45-64 \\
65+ \\
\text { Not stated }\end{array}$ & $\begin{array}{r}1 \\
3 \\
5 \\
12 \\
5\end{array}$ & $\begin{array}{l}1 \\
6 \\
0 \\
0 \\
1\end{array}$ & $\begin{array}{l}0 \\
1 \\
0 \\
0 \\
1\end{array}$ & $\begin{array}{r}26 \\
40 \\
11 \\
1 \\
5\end{array}$ & $\begin{array}{l}\mathbf{0} \\
8 \\
0 \\
0 \\
0\end{array}$ & $\begin{array}{r}13 \\
12 \\
2 \\
0 \\
2\end{array}$ & $\begin{array}{l}41 \\
70 \\
18 \\
13 \\
14\end{array}$ \\
\hline Total & 26 & 8 & 2 & 83 & 8 & 29 & 156 \\
\hline $\begin{array}{l}\text { Female } \\
0-14 \\
15-44 \\
45-59 \\
60+ \\
\text { Not stated }\end{array}$ & $\begin{array}{r}0 \\
2 \\
2 \\
14 \\
4\end{array}$ & $\begin{array}{l}5 \\
4 \\
0 \\
1 \\
1\end{array}$ & $\begin{array}{l}\mathbf{0} \\
\mathbf{0} \\
\mathbf{0} \\
\mathbf{1} \\
\mathbf{1}\end{array}$ & $\begin{array}{r}27 \\
66 \\
9 \\
4 \\
4\end{array}$ & $\begin{array}{l}\mathbf{0} \\
\mathbf{0} \\
\mathbf{0} \\
\mathbf{0} \\
\mathbf{0}\end{array}$ & $\begin{array}{r}10 \\
30 \\
4 \\
6 \\
2\end{array}$ & $\begin{array}{r}42 \\
102 \\
15 \\
26 \\
13\end{array}$ \\
\hline Total & 22 & 11 & 2 & 110 & 0 & 52 & 197 \\
\hline Total $\mathbf{M}+\mathbf{F}$ & 48 & 19 & 4 & 193 & 8 & 81 & 353 \\
\hline
\end{tabular}

\section{UPDATING}

There were 572 new registrations during a 12month period, and 353 medical records were recalled from the practice by the Executive Council (Table I). The population increased by 219 patients $(3.6 \%)$ during the year, and changes of name and address were recorded for $11 \%$ of the population.

\section{Postal Questionnaire}

A questionnaire asking for confirmation or amendment of identification details was sent to 1,643 patients listed who remained unvalidated at the end of one year: $42 \cdot 2 \%$ were returned completed, $36.6 \%$ were returned with the addressee untraced, and no replies were received from $21 \cdot 3 \%$.

In the returned circulars it was confirmed that 208 patients were no longer members of the practice, making a corrected total of 6,085 patients. This figure includes the 601 patients who could not be traced at the address last recorded on their medical record envelope. Many of these were in slum clearance areas. It also includes 349 patients who have not returned their circulars but who are presumed to have received them (Table II). The non-responders amount to $5 \cdot 8 \%$ of the corrected population, but,

TABLE II

RESPONSE TO POSTAL QUESTIONNAIRE SENT TO 1,643 PATIENTS REMAINING UNVALIDATED AFTER 31 DECEMBER 1970

\begin{tabular}{l|rr}
\hline Confirmed on list & \multicolumn{2}{|r}{} \\
Registered elsewhere & 485 \\
Reported dead & 51 & \\
Reported elsewhere & 40 & \\
& 117 & \\
\hline Total completed questionnaires & & \\
Questionnaire returned by GPO & 693 & $(42 \cdot 2 \%)$ \\
Questionnaire not returned & 601 & $(36 \cdot 6 \%)$ \\
\hline
\end{tabular}

together with the 601 patients untraced, they amount to $15.6 \%$ who cannot be located by postal questionnaire.

From the returned questionnaires new items of registration information were obtained for $6.9 \%$ of the corrected population, including 105 dates of birth and 303 items of marital status.

\section{The Household SAmple}

Analysis of data obtained by visiting 270 households showed that in $19(7.5 \%)$ at least one member of the family had been excluded from the surname/ address grouping because of a different surname. These 270 families represented 841 registered patients, and in $202(75 \%)$ of the families every member of the household was registered with the practice.

In this sample there were 277 units of two or more first-degree relatives (329 per 1,000 population) and $386 \mathrm{sib}$ pairs (457 per 1,000 population).

The age/sex structure of the listed population after validation and correction is shown in Table III.

\section{Discussion}

A general practice (G.P.) population can be listed from either Executive Council records or from the practice records.

For the present study it was decided to use practice records as a source of identification data, the reasons for the choice in this instance being as follows:

1. The degree of inflation can be greater in GP files, but it is easier to prune a list than to identify missing persons. 
TABLE III

AGE/SEX STRUCTURE OF PRACTICE LISTED POPULATION AFTER VALIDATION AND CORRECTION

\begin{tabular}{|c|c|c|c|c|}
\hline \multirow[b]{2}{*}{$\begin{array}{l}\text { Age } \\
(\mathbf{y r})\end{array}$} & \multirow[b]{2}{*}{ Sex } & \multirow[b]{2}{*}{$\begin{array}{c}\text { No. of } \\
\text { Patients }\end{array}$} & \multicolumn{2}{|c|}{ Proportion per 1,000 Population } \\
\hline & & & Practice Patients & Scotland mid- 1970 \\
\hline $0-14$ & $\begin{array}{l}\mathbf{M} \\
\mathbf{F}\end{array}$ & $\begin{array}{l}767 \\
663\end{array}$ & $\begin{array}{l}126 \\
109\end{array}$ & - \\
\hline Total & & 1,430 & 235 & 261 \\
\hline $15-44$ & $\begin{array}{l}\mathbf{M} \\
\mathbf{F}\end{array}$ & $\begin{array}{l}1,126 \\
1,454\end{array}$ & $\begin{array}{l}185 \\
239\end{array}$ & $\begin{array}{l}194 \\
193\end{array}$ \\
\hline $\begin{array}{l}45-64 \\
45-59\end{array}$ & $\underset{\mathbf{F}}{\mathbf{M}}$ & $\begin{array}{l}560 \\
505\end{array}$ & $\begin{array}{l}92 \\
83\end{array}$ & $\begin{array}{r}109 \\
93\end{array}$ \\
\hline $\begin{array}{l}65+ \\
60+\end{array}$ & $\begin{array}{l}\mathbf{M} \\
\mathbf{F}\end{array}$ & $\begin{array}{l}225 \\
517\end{array}$ & $\begin{array}{l}37 \\
85\end{array}$ & $\begin{array}{r}46 \\
104\end{array}$ \\
\hline Not stated & & 268 & 44 & - \\
\hline Total & & 6,085 & 1,000 & 1,000 \\
\hline
\end{tabular}

2. Missing and incorrect data are more easily dealt with by the GP team from their personal knowledge of the patients.

3. The GP records are more readily available, and the records for all doctors in the group are merged into one file.

4. New methods of data handling can be tested without affecting Executive Council functioning or burdening Executive Council staff.

5. The success of this project will finally depend upon GP ancillary staff, who will be more strongly motivated by involvement from the outset.

Grene and Henderson (1971) found an error of $14 \%$ in a listing of his practice taken from Executive Council records and maintained by a practice secretary. The accuracy in the study practice will be reassessed after a further year's operation.

The use of practice records for the construction of registers can, however, be justified only if it can be done with a minimum of extra work and inconvenience. This was achieved by removing the records from the practice premises at times when they were in least use and by taking advantage of activities already being undertaken by the receptionists for updating the register.

In a larger practice, however, removal of records for even a short period can be disruptive. This can be avoided without risk of transcription errors by using computer compatible recording on practice premises. The system currently used in Oxford (Perry, 1971) and the Woodside Health Centre (Boddie, 1971) is based on recording by electric typewriters fitted with a type face producing characters - suitable for optical scanning, which converts these characters directly into computer input. The attractiveness of this method is the low cost of the data preparation unit, its high degree of acceptability to secretarial staff, its versatility (since it can also be used for routine typing duties), and the legibility of its output which makes visual verification and editing easy. Suitable scanning facilities, however, must be available for listing the register.

A second system is described by Clarke et al.(1969) using a Flexowriter. This is a typewriter recording unit producing punched paper tape or edge punched cards for computer input, while a simultaneously typed copy of the data permits visual verification.

These data capture media are entirely dependent on electronic data processing techniques to be of practical use. The system described in this paper assumes the availability of a card punch machine. Circumstances will probably dictate which method is used. One method may be ideal for setting up the register, and another for the smaller but recurrent updating procedure.

The method used to validate the registered patients is one which permits many who rarely attend their doctor to be accounted for, including many who would not be traced by, or would not respond to, a postal questionnaire.

For prospective research projects a defined static population is clearly desirable. An external migration rate of less than $6 \%$ compares favourably with the migration rate in the City of Edinburgh (General Register Office, 1967) of 7.1\% (1966 Sample Census), and moreover approximately one-third who left the register remained in the same Executive Council area. At the end of one year only $15.6 \%$ of patients believed to be still registered with the practice had not been accounted for by either doctor/patient contact or postal questionnaire. It is 
presumed that approximately one-third of these $(5 \cdot 8 \%$ non-responders) can be contacted by domiciliary visiting. The remainder are inaccessible until they seek medical care, but as it is anticipated that as many as $\mathbf{9 0} \%$ of the total practice will seek medical advice in three years (Logan and Cushion, 1958), it can be expected that over that period of time a near total sample of this defined population would be available for study.

The discrepancy in Table III between the practice and national figures in the groups of $\leq 65$ years males and $\leq 60$ years females may be accounted for by our experience that many patients with missing dates of birth belong to these groups, a point to bear in mind if the register is used for geriatric care.

The excess of female patients in the 15-44 years age group may be due in part to a large local hospital nurse population cared for by the practice.

The patient's NHS number was recorded in the initial registration. Its length made it sometimes difficult to accommodate on one card type without abbreviating the address. The heterogeneity of its composition, and its absence from $16 \%$ of the records, precluded its use as a unique means of patient identification. The inconvenience of using two card types per patient in a manual system outweighed the long-term advantage of storing a number which could become a means of national record linkage. However, the development of computer facilities with consequent automation and extension of the registration has led to the reversal of this decision. A second card type is now used to capture the NHS number and maiden name when available. In conjunction with other items of identification data it is used to locate duplicate records or registrations but the patient serial number with the addition of a check digit is used for linkage purposes.

Newcombe (1968) has stressed the importance to geneticists of the construction of records of family information in retrievable form, as is being attempted in the linkage of British Columbia vital records. The surname/address grouping of the present population provides both a basic family structure and simplified clinical access without requiring special linkage data or techniques. In Britain, if there is any one point at which patient's medical records can be linked it should be the NHS cumulative medical record held by the general practitioner.

The sample of 270 families is non-random, but there is no reason to suspect a selection by family size. The figure of 277 first-degree relatives and 386 sib pairs in 270 households is therefore probably a reasonable estimate of the value of the total population for family studies.

From the outset this register has been devised in computer compatible form. This has the advantage that manipulation can be conveniently effected by computer for the construction of age/sex registers and selection of cohorts for special study when such facilities are available.

\section{SUMMARY}

A method of establishing and manually updating a register of a population largely composed of family units is described.

The register which is required for clinical, genetic, and community medical research is based on National Health Service general practitioners' lists.

In one year the reliability of the registered information was confirmed for $75 \cdot 5 \%$ of this population through doctor-patient contact.

Household units of two or more first-degree relatives accounted for $46 \%$ of all those included in the register. In $75 \%$ it is likely that the registered household comprises the total household.

Our thanks are due to Dr. W. Strachan and Dr. Fiona Maclaren for their collaboration and to Mrs. Isobel Scott and Mrs. Louisa Roberston, the practice receptionists, whose enthusiasm and continuing cooperation are essential for maintenance of the register. We are also grateful to the staff of the Medical Research Council Clinical and Population Cytogenetics Unit in Edinburgh for their support and considerable assistance with this project.

\section{REFERENCES}

Boddie, A. F. (1971). Personal communication.

Department of Health and Social Security, Welsh Office, Cenntral Health Services Council (1971). The Organisation of Group Practice. H.M.S.O., London.

Clarke, A. H., Dixon, R. A., and Rickards, D. F. (1969). "Practis". J. roy. Coll. gen. Practit., 17, 60.

Clarke, M. (1971). Recent developments in General Practice. I. Changes in list size and the effect on the practitioner's workload. Update Plus, 1, 337.

General Register Office, Edingurgh (1967). Sample Census 1966, Scotland. H.M.S.O., Edinburgh.

Grene, J. D., and Henderson, J. M. (1971). Automated recall in general practice. J. roy. Coll. gen. Practit., 21, 352.

Logan, W. P. D., and Cushion, A. A. (1958). Morbidity Statistics from General Practice, Vol. 1 (General). General Register Office Studies on Medical and Populations Subjects, No. 14. H.M.S.O., London.

Morrell, D. C., Gage, H. G., and Robinson, N. A. (1970). Patterns of demand in general practice. J. Roy. Coll. gen. Practit., 19, 331. 
Newcombe, H. B. (1968). Products from the early stages in the development of a system of linked records. In: Record Linkage in Medicine. Edited by E. D. Acheson, p.7. Livingstone, Edinburgh: Proceedings of the International Symposium, Oxford, 1967.
OCKenden, J. M., and Bodenham, K. E. (1970). Focus on Medical Computer Development. Oxford University Press for Nuffield Provincial Hospitals Trust.

Perry. J. (1971). Personal communication. 